\title{
Vibratory urticaria
}

INSERM

\section{Source}

INSERM. (1999). Orphanet: an online rare disease and orphan drug data base. Vibratory urticaria. ORPHA:493342

Vibratory urticaria is a rare, genetic urticaria characterized by the development of localized, short-lasting (resolving within 1 hour), pruritic, erythematous, edematous hives in response to repetitive frictional or vibratory stimulation of the skin, which in some cases is accompanied by facial flushing, headache or the sensation of a metallic taste. Concomitant local mast cell deg ranulation and increased histamine serum levels are additional typical findings. 